The Capital Asset Pricing Model: An Evaluation of Its Potential As a Strategic Planning Tool Author(s): Thomas H. Naylor and Francis Tapon

Source: Management Science, Vol. 28, No. 10 (Oct., 1982), pp. 1166-1173

Published by: INFORMS

Stable URL: http://www.jstor.org/stable/2630945

Accessed: 14/08/2009 00:42

Your use of the JSTOR archive indicates your acceptance of JSTOR's Terms and Conditions of Use, available at http://www.jstor.org/page/info/about/policies/terms.jsp. JSTOR's Terms and Conditions of Use provides, in part, that unless you have obtained prior permission, you may not download an entire issue of a journal or multiple copies of articles, and you may use content in the JSTOR archive only for your personal, non-commercial use.

Please contact the publisher regarding any further use of this work. Publisher contact information may be obtained at http://www.jstor.org/action/showPublisher?publisherCode=informs.

Each copy of any part of a JSTOR transmission must contain the same copyright notice that appears on the screen or printed page of such transmission.

JSTOR is a not-for-profit organization founded in 1995 to build trusted digital archives for scholarship. We work with the scholarly community to preserve their work and the materials they rely upon, and to build a common research platform that promotes the discovery and use of these resources. For more information about JSTOR, please contact support@jstor.org. 


\title{
THE CAPITAL ASSET PRICING MODEL: AN EVALUATION OF ITS POTENTIAL AS A STRATEGIC PLANNING TOOL*
}

\author{
THOMAS H. NAYLOR $†$ AND FRANCIS TAPON
}

\begin{abstract}
In this paper we provide a summary of the capital asset pricing model (CAPM) and point out how it might possibly be used as a tool for strategic planning by corporations that own a portfolio of businesses. We also point out some of the assumptions underlying the CAPM which must be satisfied if it is to be used for strategic planning. Next we include a critical appraisal of the CAPM as a strategic planning tool. Finally, we state the case for linking competitive strategy models, CAPM models, and business simulation models.

(CORPORATE PLANNING)
\end{abstract}

\section{Introduction}

The modern literature on finance [22] abounds with applications of the capital asset pricing model (CAPM), which was first developed by Sharpe [21] and Lintner [8], and is based on the earlier work of Markowitz [10]. Until recently, most of the applications of the CAPM were directed towards the problem of an individual investor involved in the selection of a portfolio of securities under conditions of risk.

Markowitz [10] showed that the variance of the return on a portfolio of financial securities depends not only on the riskiness of the individual securities in the portfolio, but also on the relationship among these securities, i.e., on the covariances between the respective securities in the portfolio. He showed that the variance of a portfolio of securities may be less than the smallest variance of an individual security if there are sufficient negative covariances ${ }^{1}$ among the securities. The optimum portfolio involves selecting that combination of securities that yields the best combination of expected return and risk which, of course, depends on the investor's utility function.

It can be shown that there is an implied equilibrium relationship between risk and return for each security. In equilibrium, a security is expected to yield a return commensurate with its unavoidable or systematic risk, which is simply the risk that cannot be avoided by diversification. The greater the unavoidable risk of a security, the greater the return expected by the investor from the security. The relationship between expected return and unavoidable risk and the valuation of securities in this context is the essence of the capital asset pricing model [22, p. 59].

The numerous financial applications of the CAPM described in the literature [7], [8], [13], [19], [21], [22] include: (1) valuation of a firm's common stock, (2) capital budgeting, (3) merger and acquisition analysis, and (4) the valuation of warrants and convertible securities. Recently, several management consulting firms, including Marakon Associates [11] and Strategic Planning Associates [4], have proposed employing the CAPM not only as a decision making tool for investors with a portfolio of financial assets, but also as a planning tool for corporations that manage a portfolio of

\footnotetext{
* Accepted by Ambar G. Rao; received May 30, 1981. This paper has been with the authors 1 month for 1 revision.

${ }^{\dagger}$ Duke University.

$\ddagger$ University of Guelph, Guelph, Ontario, Canada.

${ }^{1}$ A negative covariance between two securities can be interpreted to mean that when the return from one security is above its average value, the return from the other is below its average value.
} 
businesses, divisions, strategic business units, etc. In the latter case, the portfolio consists of tangible assets, while in the former case it consists of financial assets only.

In this paper we present a summary of the CAPM in a form that may be useful as a strategic planning tool for diversified, decentralized companies such as General Electric, Westinghouse, or Northwest Industries. We then discuss the use of the CAPM as a strategic planning tool. We conclude the essay with a critical appraisal of the CAPM as a strategic planning tool.

\section{The Capital Asset Pricing Model}

We shall consider a single corporation whose common stock is actively traded in a market consisting of a total of $n$ securities. The company is a decentralized conglomerate which presently owns $m$ different businesses.

The CAPM is based on the following assumptions: (1) All investors in securities are single period (say one year) expected utility wealth maximizers who choose securities on the basis of mean and variance of return; (2) Investors borrow or lend funds at a risk-free interest rate; (3) Investors have identical subjective estimates of the means, variances, and covariances of all securities; (4) The market for financial securities is perfectly competitive and all investors are price takers; (5) The quantity of securities is fixed; (6) All securities are perfectly divisible and liquid, i.e., marketable without significant transaction costs; (7) There are no taxes. The CAPM attempts to determine the worth of an investor's financial assets when the behavior of all investors in the stock market is taken into consideration.

To extend the CAPM to the case of a corporation that owns a portfolio of businesses, we must assume that the businesses have the same properties as securities. (More will be said about the plausibility of this assumption later in this paper.)

Suppose that we have a multi-divisional company that earns an expected but risky rate of return $R$. In order to determine the value placed on this company by the stock market, we need to know what adjustments will be made for risk on its future earnings stream. The risk associated with the company is measured by the product of the standard deviation of its own rate of return $\sigma$ and the correlation coefficient between the company's rate of return and the rate of return on the entire portfolio of all $n$ firms (securities) in the market that is denoted by $r_{m}$. This measure of risk is particularly useful because the company's risk is measured by its contribution to the standard deviation of the rate of return of the market portfolio of which the company represents a single asset or security. For example, if our particular company has a high standard deviation of the rate of return, an investment in the company might appear undesirable. However, if $r_{m}$ is zero, investors can virtually eliminate the risk by diversifying. The risk attached to a company with $r_{m}>0$ however, cannot be diversified away, and is called unavoidable or systematic risk.

Avoidable or unsystematic variable elements in the rate of return of a company also exist. However, in a portfolio these unsystematic elements are cancelled by unsystematic variations in the returns of other firms (securities). Therefore, unsystematic risk does not contribute to the variance of the rate of return of the entire portfolio of securities in the market. Therefore, the risk associated with our particular company's own rate of return measured by $\sigma$ is regarded as increasingly undesirable as $r_{m}$ approaches its maximum value of 1.0. This concept is effectively encompassed by the product $r_{m} \sigma$.

Conversely, it is possible (although rare) for some firms to have streams of profits that are negatively correlated with those of other firms in the market. Because investing in such firms allows investors to offset movements in returns of the market portfolio, they will be valued at a rate of return even lower than that of a riskless asset. Thus 
each firm's profit stream is assigned a value, and this value depends not only upon its own characteristics (its standard deviation), but also upon how it fits in with all other firms included in the market portfolio, i.e., how it modifies the variance of the return in that portfolio.

The certainty equivalent rate of return for a company can be derived by subtracting from the expected rate of return $R$ a risk premium consisting of the product of $r_{m} \sigma$, which was defined previously, and $\rho$, the market price of risk. The coefficient $\rho$ represents the rate at which the market is willing to trade extra risk (measured by $r_{m} \sigma$ ) for increased return (measured by $R$ ). Alternatively, $\rho$ denotes the value of risk reductions (increases) in terms of $R$. So long as the capital market is perfectly competitive, then $\rho$ is a constant. The risk premium implies that for every additional unit of risk $r_{m} \sigma$ borne by investors, the rate of return demanded increases by $\rho r_{m} \sigma$. Thus, the certainty equivalent rate of return required by the market for a specific company or security is equal to $R-\rho r_{m} \sigma$. The expected value of the firm $V$ is given by the following expression provided that its expected rate of return will continue indefinitely [21]:

$$
V=\frac{R-\rho r_{m} \sigma}{i}
$$

where $i$ is the risk-free interest rate.

Since the company in question owns a portfolio of $m$ different businesses, it is possible (see [10] for details) to express the variance $\sigma^{2}$ of its rate of return as:

$$
\sigma^{2}=\sum_{j=1}^{m} W_{j}^{2} \sigma_{j}^{2}+\sum_{\substack{j=1 \\ j \neq k}}^{m} \sum_{\substack{k=1 \\ k \neq j}}^{m} W_{j} W_{k} \sigma_{j k}
$$

where $W_{j}$ is the proportion of the company's total assets invested in business $j, W_{k}$ is the proportion of the company's assets invested in business $k$, and $\sigma_{j k}$ is the covariance between returns for businesses $j$ and $k$. Investment in the parent company is profitable so long as the expected value of the company $V$ is greater than the total amount $I$ invested in that company. Likewise, investment in business (or division) $j$ is profitable so long as the expected value of that business (or division) $j, V_{j}$, is greater than the amount $I_{j}$ invested in that business. $V_{j}$ takes the same form as equation (1),

$$
V_{j}=\frac{R_{j}-\rho r_{j m} \sigma_{j}}{i}
$$

where

$R_{j}=$ expected rate of return of business $j$,

$\sigma_{j}=$ standard deviation of the rate of return of business $j$,

$r_{j m}=$ correlation coefficient between the rate of return for business $j$ and the rate of return for the market portfolio of securities.

The problem of the firm under this formulation of the CAPM is to select a portfolio of businesses that maximizes the value of the company $V$.

We will now examine how these concepts may be applied to strategic planning in a conglomerate firm.

\section{The Application of the Capital Asset Pricing Model to Strategic Planning}

The strategic portfolio planning problem of the firm involves two interdependent decisions. First, management must decide which businesses in the portfolio should be retained and which businesses should be removed (divested). Second, for those businesses retained in or added to the portfolio, management must decide on the 
amount to be invested in each business. Under the CAPM framework, the primary strategic objective of management in making these two interdependent decisions is to maximize $V$, the expected value of the firm's common stock.

If we now turn to the expression for $V$ given by equation (1), we may gain some insight into how the CAPM approach can be used as a strategic planning tool. The first thing to note about equation (1) is that the company's management wields little or no influence over the risk-free interest rate $i$ and the risk premium $\rho$. The three parameters over which management has at least partial control are the company's rate of return $R$, the standard deviation of the company's rate of return $\sigma$, and the correlation coefficient between the company's rate of return and the market rate of return $r_{m}$. From equation (1), it is obvious that management should embark on a long term investment strategy that increases $R$ and decreases $\sigma$ and $r_{m}$.

Since the firm's expected rate of return $R$ is the weighted average of the expected returns from the respective businesses in its portfolio,

$$
R=\sum_{j=1}^{m} W_{j} R_{j}
$$

an integral part of the company's long term strategy should be to encourage the managers of each of the individual businesses in the company's portfolio to increase the rate of return of their respective businesses. But the rate of return on a given business depends on a variety of factors, some controllable and some not. Although the management of individual businesses may be able to control advertising expenditures, work-in-progress inventory levels, and maintenance costs, it has little or no control over the competitive environment, the regulatory environment, and the macroeconomic environment. The extent to which corporate management should be involved in individual business efforts to increase their profitability is a topic that is beyond the scope of this paper. For the moment, we shall leave this topic by noting that it is one thing to say that the businesses in the company's portfolio should increase their profitability, but it is quite another to say how this should be accomplished.

As indicated by equation (2), the variance $\sigma^{2}$ of the company's return from its entire portfolio of businesses depends not only on the variance $\sigma_{j}^{2}$ of the businesses constituting the portfolio but also on the relationship between these businesses, which is denoted by the covariance $\sigma_{j k}$. By diversifying its portfolio of businesses to include businesses with low positive covariances or even possibly negative covariances, a company can reduce the dispersion of the pobability distribution of possible returns relative to the expected value of return for that distribution. As a result of diversification, the company reduces its risk ( $\sigma)$ from owning various businesses. Thus, in terms of equation (2), the company should pursue a strategy of acquiring businesses with low variances $\left(\sigma_{j}^{2}\right)$ and negative covariances of return $\left(\sigma_{j k}\right)$. Obviously, finding businesses with these statistical properties may not be easy. However, if a company is searching a financial database such as COMPUSTAT, Value Line, or PIMS [20] to find possible acquisition candidates, then the guidelines outlined above may be useful. That is, the database could be screened for those businesses that meet some predetermined criteria with regard to variances and covariances.

The last parameter in equation (1) that is at least partially controllable by management is $r_{m}$, the correlation between the company's rate of return and the rate of return on the entire market portfolio (not to be confused with the company's own portfolio). Obviously, a portfolio should be designed so that $r_{m}$ is as close to zero as possible or maybe even negative.

The result of the strategies-acquisitions or divestitures-which we have outlined may be easily understood by referring to equation (1). For a given return $(R)$, these 
policies would increase the numerator of equation (1) and hence raise the value $(V)$ of the conglomerate firm's shares.

An example of a large firm that has pursued such a diversification strategy is provided by Northwest Industries Inc. This company owns directly or indirectly a number of businesses engaged in such diverse fields as the manufacturing and marketing of industrial, chemical, and consumer products. Industrial products include tubular steel and ingot molds, connecting devices, and electrical lamp ballasts. Chemical products are specialty pesticides and industrial chemicals. Consumer products include apparel, automobile replacement batteries, and beverages (primarily soft drinks and Scotch whiskey). The philosophy of the firm is, first, to operate in fields that are basic-in the sense that Northwest's products are commonplace and will always be purchased-and diverse, and second, to be the leader in each of these industries. The result of this diversification strategy is that the covariance of returns between businesses (e.g., industrial and consumer products) is kept much lower than if Northwest Industries concentrated its investments in one field alone. In addition, the stress put by management on owning only well-known brands in each field guarantees steady returns, and thus keeps the variance of each division's returns as low as possible. The firm also invests overseas, in order, among other reasons, to keep the correlation between the company's rate or return and the rate of return on the entire U.S. market portfolio as close to zero as possible. Therefore, Northwest Industries' overall variance of return and the correlation of its returns with those of the market are minimized. We can see from equation (1) that, for a given $R$, these policies raise the value of the firm on the stock market.

In summary, in building a portfolio of businesses, a company should strive for high returns $R_{j}$ on each business, low variances $\sigma_{j}^{2}$, negative covariances $\sigma_{j k}$, and values of $r_{m}$ that are close to zero or negative.

\section{A Critical Appraisal of the Capital Asset Pricing Model}

Although the capital asset pricing model is attractive as a strategic planning tool, it suffers from a number of serious limitations, some of which are summarized below:

1. Although the assumptions underlying the CAPM may be perfectly reasonable for a portfolio of purely financial assets including common stocks, bonds, and other securities, they may not hold true for a portfolio of actual businesses. The assets of a business might include financial assets, plant and equipment, inventories, an organizational structure, an experienced staff, and possibly good will. The parent company may experience considerable difficulty in attempting to divide the company's assets, functions, and employees into free-standing elements that in fact have a considerable degree of autonomy. There may also be an exit problem for a particular business in a company's portfolio due to a lack of realistic second-hand markets and options for selling the business caused by asset specialization, shared resources, commitments to the workforce, and regulatory constraints. For example, several years ago Northwest Industries might have found it difficult to divest itself of an operating company known as Velsicol, due to the potential liability associated with a series of lawsuits pending against the company. Finally, a number of behavioral problems could also affect the divisibility and liquidity of a business. The value of a business could be reduced to almost zero if either its management or key members of its technical staff were planning to leave the business if it were sold.

2. The calculation of the expected value $V$ and the use of expected value maximization as a decision criterion depend substantially on the Law of Large Numbers, whereby the expected value is reduced to a quasi-certain value over a large number of 
replications. $^{2}$ The expected value criterion was designed for use in a repetitive environment such as gambling or insurance. In some cases the Law of Large Numbers, and hence the expected value criterion, is an inappropriate decision rule. Such a case is the "one shot" decision, in which a single decision must be made in a non-replicable environment. Consider a conglomerate in which management desires to make a single decision about a particular acquisition based on the $a$ priori probability distribution of the rate of return for the proposed acquisition during the past five years. To some extent it can be argued that the a priori probability distribution of the rate of return, based on past experience, is of limited use for a particular time period in the future, say the next five years. For these data to be useful, we would want to be able to replicate the business experience of the proposed acquisition for a series of five-year periods, not just for a single five-year span. The use of the expected value criterion has also been criticized because the Law of Large Numbers requires successive replications to be statistically independent. This is virtually impossible to achieve in a business environment.

3. Another source of dissatisfaction with the expected value criterion is its failure to consider extreme values of random variables. That is, there are chance prospects for which the expected value is theoretically infinite, and yet no reasonable decision maker will accept the risk unless he or she is paid a handsome sum. This paradox is often referred to as the St. Petersburg Paradox.

4. The entire analysis underlying the CAPM assumes that we can estimate $R, r_{m}$, and $\sigma$ for the company as a whole, as well as for each business unit. There is an implicit assumption that management can either directly or indirectly affect these parameters. Not only is management unable to exercise a high degree of control over these parameters, but there may be a host of practical and statistical problems involved in estimating them in the first place.

First, estimates of risk and return for a portfolio of financial securities are completely determined by financial markets. Yet for business units belonging to a conglomerate there may be little or no market data from which to estimate these parameters. Second, there is a question as to who provides these parameter estimates for a particular business unit. If the general manager of the particular business is asked to provide the parameter estimates based on his or her essential knowledge of the business in question, then how can you avoid "gaming" on the part of the general manager, given that it will be quite clear what is at stake. On the other hand, if the estimates are provided by the staff or outside consultants, then the estimates may be lacking in business realism. Third, parameter estimates of risk and return for a portfolio of actual businesses involve a combination of time-series and cross-sectional data from businesses which may not be independent.

5. The CAPM is essentially a static equilibrium model. Yet the problem of deciding which businesses a company is going to hold and the level of investment to make in each business is essentially a dynamic problem. There is some doubt as to the relevance of a static equilibrium model to a dynamic investment problem.

6. If an investment banker is managing a portfolio of securities, he or she may very well be interested in only the three parameters listed above, as well as the market value of the portfolio. With the management of purely financial assets, risk and return are the entire ballgame. But in the case of a portfolio of businesses, top management must take a host of economic, behavioral, political, organizational, social, and regulatory factors into consideration when evaluating strategic plans. In other words, strategic

\footnotetext{
${ }^{2}$ The Law of Large Numbers states that if in $n$ identical replications of an experiment $X_{i}$ occurs $k$ times, and if $n$ is very large, then $k / n$ approaches the probability $P_{i}$ that $X_{i}$ occurs.
} 
planning is a multi-dimensional problem that cannot easily be reduced to a single variable such as $V$, the value of the company.

\section{Summary and Conclusions}

In spite of the limitations outlined above, capital asset pricing models appear to offer a company that owns a portfolio of risky businesses a useful conceptual framework for viewing the problem of long term strategic planning. However, this conceptual framework is merely one of several options available to strategic planners. Among the other options available are competitive strategy models, deterministic portfolio optimization models, and corporate simulation models.

Competitive strategy models [1], [15], [18] of the type proposed by The Boston Consulting Group [6], Arthur D. Little, McKinsey, and more recently by Michael Porter [18], all have a quite different focus. Whereas the capital asset pricing models concentrate on risk, return, and the value of a business, the competitive strategy models apply such well-known concepts as the growth share matrix and the experience curve [1], [15] to the overall problem of competitive strategy. That is, emphasis is not on the interdependence of businesses with each other, but on their interdependence with their competitors. Clearly, competitive strategy is an important element in a company's overall strategic plan.

On the other hand, corporate simulation models [14] enable management to examine a variety of strategic options, and to evaluate their consequences on a multiplicity of financial, marketing, and production indicators. To be useful to management, capital asset pricing models must be linked to some type of corporate simulation model. That is, one can envisage a series of business simulation models, one for each business in the company's portfolio, each of which generates a value for $R_{j}$ and $\sigma_{j}$ for that business as well as other output variables of interest to management. A corporate consolidation model that computes the value of the company $V$ from equation (1) would also be needed. This consolidated model must in addition treat the interdependencies among the businesses in the company's portfolio through equation (2), and the company's interdependence with the market portfolio through $r_{m}$. Specifically, the consolidated model must have a capability to compute $R, r_{m}, \sigma$, and finally $V$, from equation (1).

In short, we are suggesting the use of the capital asset pricing model conceptual framework as an important output of a corporate simulation model. Likewise, the growth share matrix and experience curves advocated by The Boston Consulting Group and others might be treated as outputs of business simulation models.

Specifically, what we are suggesting is that the vendors of computer based planning software systems [17] such as CUFFS, EXPRESS, FCS, and IFPS consider the possibility of including built-in subroutines that can calculate the risk and return parameters for each business being simulated as well as the consolidated company as a whole. There is already evidence that some software vendors are beginning to build in growth share matrices and experience curves as optional ways to display output data from business simulation models.

Perhaps the major advantage of linking business simulation models to competitive strategy models and CAPM models is that business simulation models can substantially improve the explanatory power of both competitive strategy models and CAPM models by linking each of these analytical tools back to a model of the firm based on sound economic theory. Thus competitive strategy models and CAPM models become powerful expository instruments for evaluating the economic and financial consequences of alternative strategies which may be pursued by a given business or portfolio of businesses.

Finally, the deterministic portfolio optimization models of the type proposed by Hamilton and Moses [5] represent yet another option for strategic planning. Although 
this methodology is for the most part untested in the corporate environment, some companies that have accumulated considerable experience with corporate simulation models during the 1970s are beginning to experiment with the use of optimization models as strategic planning tools. Obviously, at least in theory, one could contemplate models that attempt to optimize the value of the firm $V$.

In summary, we believe that capital asset pricing models do offer some promise as a conceptual framework for strategic planning in companies which manage a portfolio of businesses. In no sense should management rely exclusively on the narrow criteria of risk, return, and value of the business to make strategic decision. However, the capital asset pricing model framework combined with the competitive strategy models of The Boston Consulting Group, and a linkage to corporate simulation models may offer management an extremely powerful analytical tool for strategic planning.,

\footnotetext{
${ }^{3}$ One of the referees of this paper has made the interesting suggestion that the CAPM might provide a useful analytical framework to evaluate some of the models proposed by Michael Porter in his book, Competitive Strategy [18]. For example, the CAPM might provide an explanation as to why there are strategic groups in some industries, in which a group of firms follow the same or a similar strategy.

${ }^{4}$ This research was partially supported by funds from the Corporate Economics Program at Duke University. We are indebted to Michele H. Mann for editorial assistance.
}

\section{References}

1. Abel, Derek F. and Hammond, John S., Strategic Market Planning, Prentice-Hall, Englewood Cliffs, N.J., 1979.

2. Ackoff, Russell L., A Concept of Corporate Planning, Wiley, New York, 1972.

3. Ansoff, H. Igor, Strategic Management, Wiley, New York, 1979.

4. Graham, Michael R., "Capital Market Models and Their Implication for Strategy Formulation," in Corporate Strategy: The Integration of Corporate Planning Models and Economics, Thomas H. Naylor (editor), North-Holland, Amsterdam, 1982.

$\rightarrow$ Hamilton, W. F. And Moses, M. A., "An Optimization Model for Corporate Financial Planning," Operations Res., Vol. 21 (May-June 1973), pp. 677-692.

6. Henderson, Bruce D., Henderson on Corporate Strategy. Abt, Cambridge, Mass., 1979.

7. Jensen, Michael C., "Capital Markets: Theory and Evidence," Bell J. Econom. Management Sci., Vol. 3 (Autumn 1972), pp. 371-391.

8. Linter, JoHN, "The Valuation of Risk Assets and the Selection of Risky Investments in Stock Portfolios and Capital Budgets," Rev. Econom. Statist. Vol. 47 (February 1965), pp. 13-37.

9. Lorange, Peter and Vancil, Richard F., Strategic Planning Systems, Prentice-Hall, Englewood Cliffs, N.J., 1977.

10. Markowitz, H., Portfolio Selection, Cowles Foundation Monograph No. 16, Wiley, New York, 1959.

11. McGrath, James P., "Criteria for Determining an Optimal Business Portfolio," unpublished paper presented at the meeting of The Institute of Management Sciences, November 11, 1980.

12. Modigliani, Franco and Miller, Merton H., "The Cost of Capital, Corporation Finance and the Theory of Investment," Amer. Econom. Rev., Vol. 48 (June 1958), pp. 261-277.

13. Mossin, JAN, "Equilibrium in a Capital Asset Model," Econometrica, Vol. 34 (October 1966), pp. $768-775$.

14. NaYlor, Thomas H., Corporate Planning Models, Addison-Wesley, Reading, Mass., 1979.

15. - Strategic Planning Management, Planning Executives Institute, Oxford, Ohio, 1980.

16. - (editor), Corporate Strategy: The Integration of Corporate Planning Models and Economics, North-Holland, Amsterdam, 1982.

17. - AND ManN, Michele H. (editors), Computer Based Planning Systems, Planning Executives Institute, Oxford, Ohio, 1982.

18. Porter, Michael E., Competitive Strategy, Free Press, New York, 1980.

19. Ross, StePhen A., "The Current Status of the Capital Asset Pricing Model (CAPM)," J. Finance, Vol. 33 (June 1978), pp. 885-901.

20. Schoeffler, Sidney, Buzzell, R. And Heany, R., "Impact of Strategic Planning on Profit Planning," Harvard Business Rev., Vol. 52 (March-April 1974), pp. 137-145.

21. Sharpe, William F., "Capital Asset Prices: A Theory of Market Equilibrium under Conditions of Risk," J. Finance, Vol. 19 (September 1964), pp. 425-442.

22. Van Horne, James C., Financial Management and Policy, Prentice-Hall, Englewood Cliffs, N.J., 1980. 